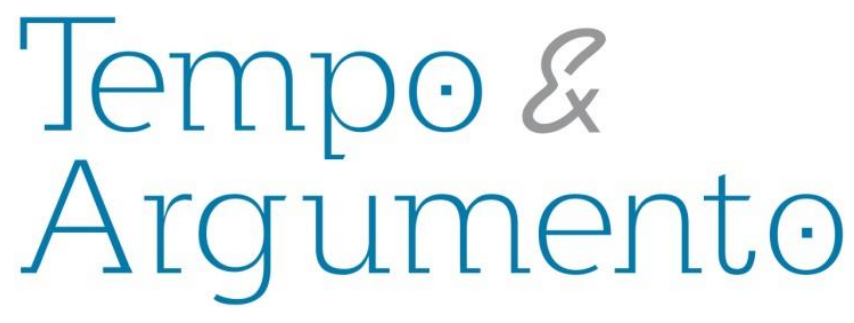

\title{
Mediação cultural: experiências, percursos e estratégias intelectuais
}

\section{Resenha da obra:}

GOMES, Angela de Castro; HANSEN, Patricia Santos (Orgs.). Intelectuais Mediadores: práticas culturais e ação política. Rio de Janeiro: Civilização Brasileira, 2016. 488 p.

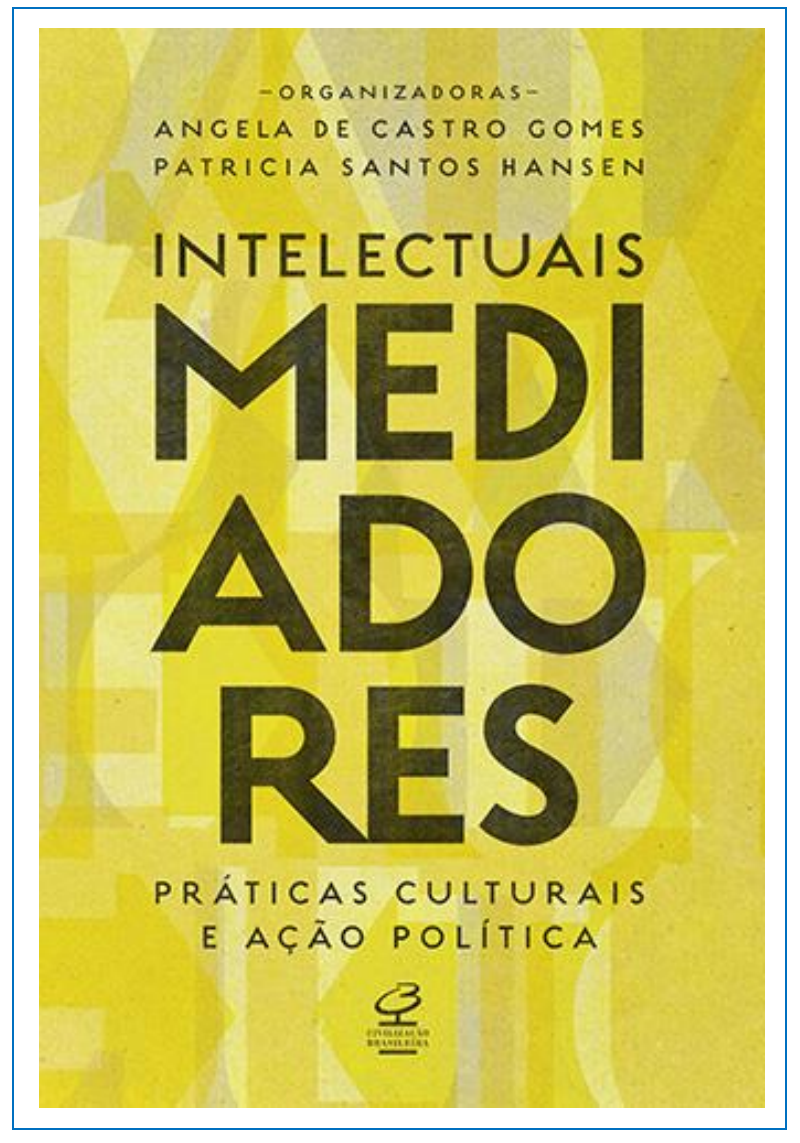

\section{Autora da resenha}

\section{Márcia Regina dos Santos}

Doutoranda no Programa de Pós-Graduação em História da Universidade do

Estado de Santa Catarina.

Brasil

marcia0705@gmail.com

\section{Para citar esta resenha:}

SANTOS, Márcia Regina dos. Mediação cultural: experiências, percursos e estratégias intelectuais. Revista Tempo e Argumento, Florianópolis, v. 8, n. 19, p. 380 - 385. set./dez. 2016. 
A obra Intelectuais Mediadores: práticas culturais e ação política, organizada pelas historiadoras Angela de Castro Gomes e Patricia Santos Hansen reuniu um total de quatorze autores, os quais se dedicaram a ampliar o debate sobre as questões que tratam das práticas culturais protagonizadas por sujeitos históricos identificados como intelectuais. Angela de Castro Gomes, graduada em História pela Universidade Federal Fluminense (1969), Mestra e Doutora em Ciência Política (Ciência Política e Sociologia) pela Sociedade Brasileira de Instrução (SBI/IUPERJ-1987), constituiu-se uma importante referência com pesquisas nos temas de história política do Brasil República, história de intelectuais, cidadania e direitos do trabalho, Justiça do Trabalho, historiografia, memória e ensino de história. É o seu quinquagésimo livro entre publicações, organizações e edições e, foi organizado em parceria com a também historiadora Patricia Santos Hansen, graduada em História pela Pontifícia Universidade Católica do Rio de Janeiro (PUC-Rio, 1998), Mestra em História Social da Cultura pela mesma instituição (2000) e Doutora em História Social pela Universidade de São Paulo (FFLCH-USP, 2007). O livro apresenta uma proposta de refinamento teórico, o qual visa a debater as operações culturais que foram multiplicando e diversificando as formas de disseminar conhecimentos e a mediação cultural que ocorre por diversos meios, sujeitos e escalas. Num movimento de ampliar a significação do intelectual contemporâneo, a autora denomina-os como "homens da produção de conhecimento e comunicação de ideias, direta ou indiretamente vinculados à intervenção político-social” (p. 10). Dessa forma, oferece estudos desenvolvidos na mesma direção, a qual problematiza e debate a ação de alguns homens e mulheres como mediadores culturais.

Os artigos que compõem a obra estão organizados em três partes. A primeira parte do livro, nomeada de Trajetórias e projetos, agrupou textos sob a perspectiva da ação de intelectuais no âmbito da tradução e edição, bem como, os percursos por eles realizados num processo de disseminação de livros e textos. O artigo de Kaomi Kodama delineia o campo de atuação do ator social, o qual compreendeu como "vulgarizador" (p. 42), a partir das traduções da obra de Louis Figuier que circularam no Brasil. A ideia de mediação estava focada em apresentar as novidades científicas para um público não especializado com objetivo de educar pela ciência. A autora Patrícia Tavares Raffaini 

produções de sentidos. O artigo de Ângela de Castro Gomes apresenta a mediação entrecruzada por um projeto literário de intercâmbio luso-brasileiro infantil promovido pela autora/editora lusa Ana de Castro Osório. Por meio de obras que têm personagens viajantes que vivenciam a cultura do outro, a autora/editora investe seus esforços em projetos que poderiam ser nomeados de mediação cultural transnacional.

No âmbito educacional, evidenciando uma dimensão política na mediação cultural, a autora Gabriela Pellegrino Soares debate a atuação de professores em diferentes regiões do Vice-Reino da Nova Espanha (hoje, região do México), no sentido de que disseminaram ferramentas culturais - e também políticas - as quais contribuíram nos sentidos e práticas da participação camponesa na Revolução Mexicana, deflagrada em 1910. Diferentemente do olhar coletivo sobre uma classe de intelectuais, o autor Joaquim Pintassilgo estudou o percurso biográfico de Orbelino Geraldes Ferreira e a sua relação com o estabelecimento de uma vertente pedagógica chamada "escola ativa" (p. 148), em Portugal, durante o regime salazarista. Os dois últimos artigos dialogam no sentido de discutirem diferentes escalas de mediação, em diferentes lugares sociais. No primeiro caso, a mediação promovida na região rural, com materiais distribuídos para o letramento de populações com dificuldades de recursos e, no segundo caso, a mediação promovida a partir de cargos docentes que possibilitaram a produção de livros e a disseminação de ideias. No entanto, ambos ocorrem em situações adversas, nas quais os mediadores oscilaram entre promover a ilustração e não se expor às austeridades políticas do período.

A segunda parte da obra nomeada Lugares e mídias aborda a ação dos intelectuais mediadores por meio dos suportes de divulgação utilizados. O artigo de Ana Paula Sampaio Caldeira discutiu a atuação de Benjamin Franklin Ramiz, quando esteve à frente da Biblioteca Nacional, na concretização do projeto editorial dos Anais da Biblioteca Nacional. Num esforço de inserir a Biblioteca nas práticas internacionais de circulação e divulgação cultural, Ramiz mobilizou outros intelectuais da época para contribuir nas 
referência como intelectual de sua geração. $\mathrm{O}$ artigo de Eliana Dutra discutiu os contextos de mediação intelectual. Nesse sentido, abordou o caráter transnacional e transcultural da mediação por meio da circulação das revistas elaboradas para disseminar entre os países o que era produzido. Foram analisadas revistas do Brasil, Argentina e França para pensar uma possível triangulação de produções literárias que, por conseguinte, divulgavam concepções identitárias. O artigo de Francisco Palomanes Martinho tratou da mediação na questão dos discursos disseminados pela revista antiliberal e antidemocrática intitulada "Ordem Nova”. Os redatores da revista, em especial Marcello Caetano apoiavam um retorno monárquico às vésperas do golpe de Estado que mergulharia Portugal num período ditatorial. Revisitando teorias e acontecimentos históricos que se reportavam aos primórdios do liberalismo, os redatores elaboravam uma mediação político-cultural, com vistas a fortalecer sua ideologia antidemocrática. Sob a perspectiva da mediação pela oralidade, o artigo de Giovane José da Silva analisa os scripts dos programas de "Metodologia da História do Brasil" do projeto "Universidade no Ar", escritos e narrados por Jonathas Serrano. Nesse contexto, ainda que a mediação ocorresse pela oralidade transmitida pelo rádio, foi privilegiada a perenidade do suporte escrito utilizando o envio de materiais aos inscritos na formação por meio do sistema de correios, configurando assim, um aprendizado específico, mesclado por narrativas orais e escritas.

Na terceira e última parte da obra, nomeada Leituras e ressonâncias, o conjunto de textos tem como foco as apropriações, releituras e aproximações feitas acerca de obras, autores e veículos de comunicação em relação às conjunturas vigentes em tempos e espaços demarcados. O artigo de Mara Cristina de Matos Rodrigues problematiza a noção de intelectual mediador a partir da articulação entre criação e mediação intelectual na trajetória de Érico Veríssimo. A autora discute os múltiplos tempos e lugares experienciados pelo autor, os quais lhe conferiram atuação tanto na mediação de conhecimentos históricos para um público infantil escolar, no diálogo cultural 

sobre a ampliação do entendimento de mediação. O artigo de Luciano Mendes de Faria Filho aborda a problemática da elaboração dos prefácios para obras já escritas e como as redes de sociabilidades podem interferir na produção de sentidos. O projeto em questão se refere à publicação das obras completas de Rui Barbosa. A sociabilidade do responsável pelo projeto editorial - Gustavo Capanema - mobilizou intelectuais que corroborassem com a política da publicação, incidindo sobre a forma como a obra foi prefaciada e os direcionamentos da leitura. Esse tipo de mediação intelectual tem, inclusive, argumentos para descaracterizar o próprio conteúdo da obra, uma vez que, os prefácios funcionam como protocolos de leitura. Nessa mesma clave, o artigo de Patricia Santos Hansen aborda a edição da obra A defesa nacional em comemoração ao centenário de seu autor, Olavo Bilac. A autora debate a problemática da apropriação dos escritos numa perspectiva de atender demandas políticas posteriores à publicação em, pelo menos, meio século. Da mesma forma, é possível perceber uma subversão narrativa na mediação entre diferentes culturas políticas.

Os dois últimos artigos são convergentes na questão da identificação de sujeitos históricos como intelectuais. O artigo de Giselle Martins Venâncio destaca as tensões da “fundação de uma prática historiográfica dita moderna” (p. 437) por meio da análise da mediação intelectual elaborada no âmbito das publicações de coleções e revistas científicas que se mobilizaram em notabilizar uma historiografia nacional. Nesse sentido, a autora aponta a emergência de nomes e grupos que estabilizaram como referenciais ao passo que outros, permaneceram invisibilizados. Por fim, a historiadora Libânia Nacif Xavier propõe em seu artigo a construção de "interfaces entre a história da educação e a história social e política dos intelectuais" (p. 464). Num diálogo acerca dos conceitos de redes de sociabilidade, trajetórias intelectuais e geração, a autora problematiza o lugar dos sujeitos classificados como intelectuais e a sua atuação na mediação. Num esforço teórico de ampliar o entendimento do conceito de intelectuais mediadores como categoria de análise nas pesquisas, a autora infere sobre a necessidade de construir uma 
sensibilidade para que o historiador, ao munir-se de fontes, conceitos e pesquisas, priorize as escolhas que melhor contribuam para os seus objetivos. E, nesse sentido, compreender e visibilizar os homens e mulheres que atuaram na produção e disseminação cultural do país e do mundo.

Recebido em 21/11/2016 Aprovado em 04/12/2016 